\title{
Remarkably diverse and contrasting archaeal communities in a large arctic river and the coastal Arctic Ocean
}

\author{
Pierre E. Galand ${ }^{1, *}$, Connie Lovejoy ${ }^{1}$, Warwick F. Vincent ${ }^{2}$ \\ ${ }^{1}$ Département de Biologie et Québec-Océan, and ${ }^{2}$ Département de Biologie et Centre d'études nordiques, Université Laval, \\ Québec G1K 7P4, Canada
}

\begin{abstract}
Although the microbial biodiversity of arctic seas has received an increasing amount of attention, little is known about the microbial communities of its inflowing rivers. In this study we examined the molecular diversity of Archaea in the largest arctic river in North America, the Mackenzie River, and in the adjacent coastal Beaufort Sea (Canadian Arctic) during maximum open water conditions (October 2002). The Mackenzie River 16S rRNA clone libraries revealed a remarkably diverse assemblage of archaeal sequences, with an estimated 286 phylotypes defined as sequences with $97 \%$ similarity. These grouped mainly within 2 phylogenetic clusters, and were related to sequences earlier retrieved from flooded soils and sediments previously named RC-V and LDS. The marine coastal libraries were of very different composition to those of river libraries and were dominated by Group II Euryarchaeota followed by Group I Crenarchaeota. These coastal assemblages had greater archaeal diversity (18 to 23 phylotypes) than previously reported for marine communities elsewhere, and differed from previously described central Arctic Ocean assemblages. This may reflect the heterogeneous mixture of organic substrates and particles available for microbial heterotrophy in arctic coastal waters and the use of an alternative primer pair (109f-915r) in this study. The coastal sequences grouped within typical marine clusters, and we therefore conclude that they were an active autochthonous community rather than one derived from the large inflowing river. These results underscore the rich microbial diversity in arctic rivers and their adjacent coastal marine ecosystems.
\end{abstract}

KEY WORDS: Taxonomic diversity · Archaea $\cdot$ SSU rDNA $\cdot$ Canadian Arctic $\cdot$ RFLP $~$ Cloning Resale or republication not permitted without written consent of the publisher

\section{INTRODUCTION}

The Arctic Ocean and surrounding seas are strongly influenced by the inflow of fresh water from large rivers (Carmack \& MacDonald 2002). The Mackenzie River in northwestern Canada is the largest arctic river in North America, and extends $1600 \mathrm{~km}$ from Great Slave Lake to the Beaufort Sea. It is one of the most important sources of sediments to the Arctic Ocean (Carson et al. 1998) and its discharge onto the Beaufort Shelf results in coastal waters that are rich in suspended particles. Owing to their specific properties and vulnerability to ongoing climate change (Serreze et al. 2000), these habitats have inspired growing interest in the microbial ecology of coastal arctic ecosystems. Several studies applying fluorescence in situ hybridization (FISH) using domain-specific probes have found relatively high concentrations of Archaea in nepheloid (particle-rich) layers in the Beaufort Sea (2.3 to $13 \%$ of total cells, Wells \& Deming 2003) and in samples from the inflowing river and inshore coastal zone of the Beaufort Sea (up to $15 \%$ of total cells, Garneau et al. 2006, Wells et al. 2006). The statistical relationship between Archaea and particles, the detection of high archaeal concentrations in the Mackenzie River, and the correlation between Archaea and par- 
ticulate organic nitrogen (PON) suggested an allochthonous, riverine origin of Archaea over the Beaufort Shelf (Wells et al. 2006).

Molecular tools, especially environmental 16S rDNA surveys, have revealed diverse archaeal communities in many terrestrial and aquatic ecosystems (Stein \& Simon 1996). In freshwaters, planktonic Archaea diversity is primarily described from lakes (Ovreas et al. 1997, Jurgens et al. 2000, Keough et al. 2003), but there is little data on Archaea from rivers. The very few sequences reported from rivers are associated with Methanomicrobiales, Thermoplasmatales (Dumestre et al. 2002, Gonzalez-Toril et al. 2003) and Group I.1a, I.3 Crenarchaeota (Crump \& Baross 2000). A recent study on Bacteria in 2 temperate rivers revealed diverse assemblages that may represent a combination of allochthonous and autochthonous organisms (Crump \& Hobbie 2005).

In contrast to the paucity of data from rivers, there have been many reports on Archaea in the ocean since their discovery as a widespread constituent of marine plankton (Fuhrman et al. 1992). In general, the diversity of Archaea is thought to be low (Massana et al. 2000), despite the large variations in water mass properties among different oceanic regions. Within the 2 major kingdoms of Archaea - the Euryarchaeota and the Crenarchaeota - the majority of the world's oceans are dominated by a few phylotypes. Most Crenarchaeota sequences belong to Group I, whereas most Euryarchaeota are from Group II (for cluster naming see Delong 1998). In the Southern Ocean, the abundance and diversity of Archaea has been widely documented (Delong et al. 1994, Murray et al. 1998, Church et al. 2003), and Group I Crenarchaeota are thought to dominate the archaeal community throughout the water column (DeLong et al. 1998, Massana et al. 2000). In the Arctic, the description of marine archaeal diversity is limited to few studies and, in the central Arctic Ocean, two-thirds of the clones retrieved from the surface mixed layers belonged to Group I Crenarchaeota (Bano et al. 2004). No study has described the phylogenetic diversity of Archaea in coastal arctic ecosystems despite the increasing focus of attention on north polar environments resulting from climate change concerns.

In the present study, we addressed the hypothesis that Archaea in the Beaufort Shelf ecosystem are derived from riverine inputs. Samples were collected in the Mackenzie River and coastal Beaufort Shelf along a gradient of decreasing particle concentration. The marine samples were size-fractionated to assess the particle-based, allochthonous origin of the coastal Archaea populations. The diversity of the archaeal assemblages was evaluated by cloning and sequencing the PCR-amplified archaeal 16S rRNA gene using a primer set that, to date, has been applied to soils but not aquatic ecosystems. The results proved to be counter to the 'allochthonous origin' hypothesis and revealed a striking diversity of Archaea, with little overlap of phylotypes between the river and the coastal Arctic Ocean.

\section{MATERIALS AND METHODS}

Sample collection and DNA extraction. Samples were collected at stations in the Mackenzie River and Beaufort Shelf from 2 to 8 October 2002 within the framework of the Canada Arctic Shelf Exchange Study (CASES). Samples were taken along a south-north transect encompassing 2 river stations (R1 and R2, Fig. 1), 1 coastal inshore station inside the $20 \mathrm{~m}$ isobath (Z2, Fig. 1), and 1 offshore station (65, Fig. 1). R1 and R2 were sampled from a ship-based helicopter and Z2 from a small boat (Zodiac) with a 51 Go-Flow bottle and an SBE-19 CTD profiler. Stn 65 was sampled from the icebreaker CCGS Pierre Radisson' with 121 Niskin bottles mounted on an SBE Carousel Rosette system equipped with an SBE911-plus CTD profiler. Microbial biomass was collected by filtering 1 to 21 of seawater through a $47 \mathrm{~mm}$ diameter $0.2 \mu \mathrm{m}$ Durapore filter (Millipore). Sea samples were also filtered onto a $47 \mathrm{~mm}$ diameter, $3 \mu \mathrm{m}$ pore-size polycarbonate filter to assess potential 'particle-associated' communities. Filters were stored in buffer ( $50 \mathrm{mM}$ Tris, $40 \mathrm{mM}$ EDTA and $0.75 \mathrm{M}$ sucrose) and frozen at $-70^{\circ} \mathrm{C}$ until nucleic acid was extracted as described by Massana et al. (1997).

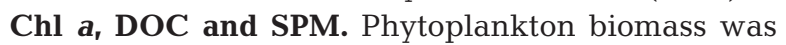
estimated from chlorophyll a ( $\mathrm{chl}$ a) concentrations determined from particulates filtered onto GF/F filters and measured fluorometrically (Strickland \& Parsons 1972, Nusch 1980). Samples for suspended particulate matter (SPM) were filtered through pre-combusted and pre-weighed GF/F filters, rinsed with $10 \mathrm{ml}$ of $1 \%$ ammonium formate to dissolve salts, and stored in petri dishes at $-20^{\circ} \mathrm{C}$. The filters were subsequently dried at $60^{\circ} \mathrm{C}$ and re-weighed for final determination of SPM (Williams 1985). Samples for dissolved organic carbon (DOC) were filtered through $0.2 \mu \mathrm{m}$ membrane filters and stored in the dark at $4^{\circ} \mathrm{C}$ until analyzed by high temperature combustion/direct injection into a gas analyzer (Knap et al. 1996).

Cloning, RFLP, and sequencing. A portion of the $16 \mathrm{~S}$ rRNA gene was amplified by PCR with the archaeal specific primers $109 \mathrm{f}$ and $915 \mathrm{r}$ (Grosskopf et al. 1998a). The $50 \mu \mathrm{l}$ PCR mixture contained $20 \mathrm{pmol}$ of the appropriate primer pairs, $200 \mu \mathrm{M}$ dNTPs, 1 U iTaq DNA polymerase (Bio-Rad), PCR reaction buffer and $1 \mu \mathrm{l}$ of template. Bovine serum albumin $\left(0.1 \mu \mathrm{g} \mathrm{\mu l}^{-1}\right)$ was added to the mix to prevent PCR inhibition. The reac- 


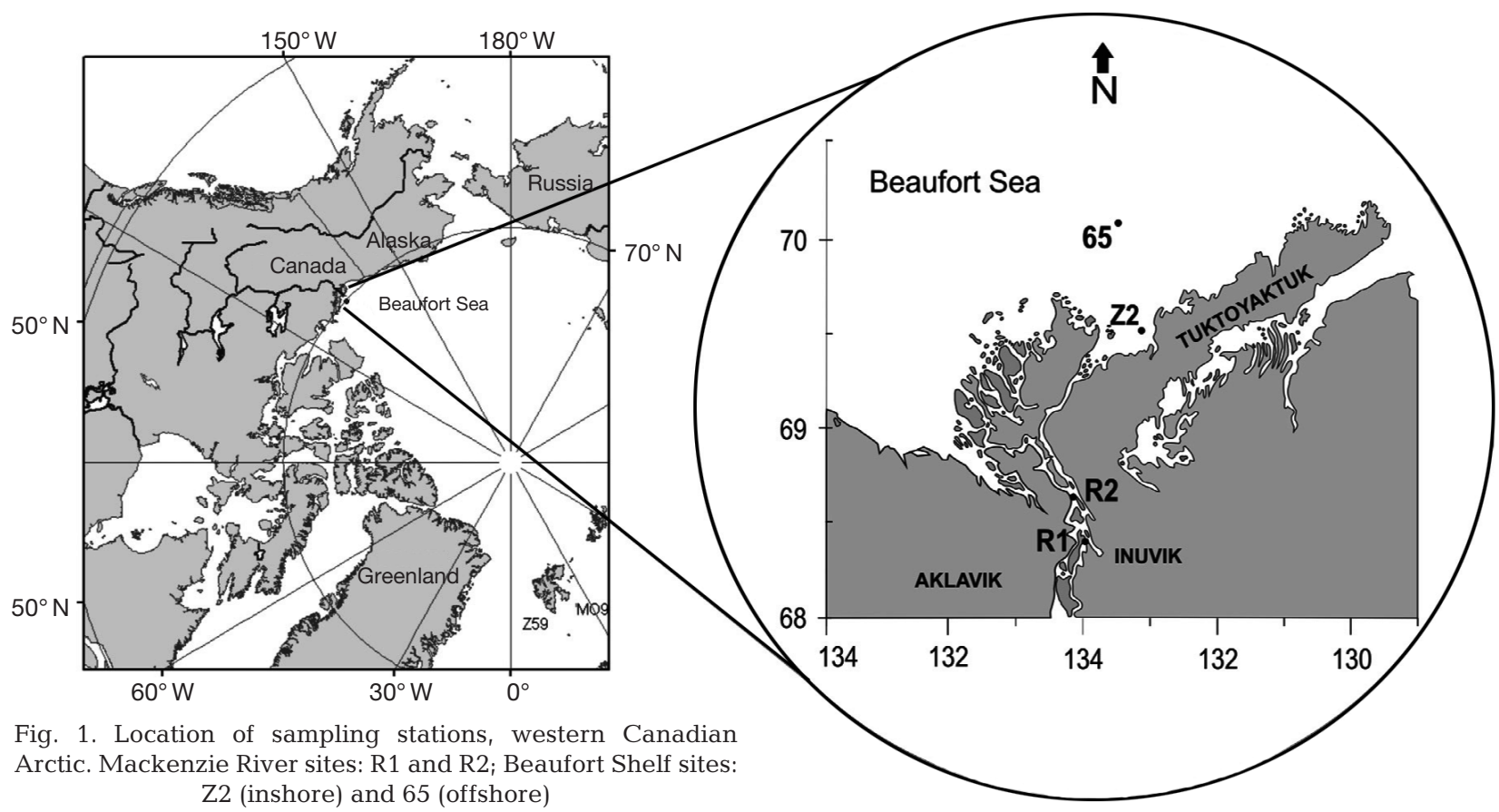

tion conditions were 35 cycles of $94^{\circ} \mathrm{C}$ for $45 \mathrm{~s}, 52^{\circ} \mathrm{C}$ for $1 \mathrm{~min}$, and $72^{\circ} \mathrm{C}$ for $1 \mathrm{~min}$. PCR products were analyzed by gel electrophoresis, purified with Qiaquick PCR Purification Kit (Qiagen), and cloned with TA cloning kit (Invitrogen) according to the manufacturer's instructions. We constructed 6 clone libraries in total: 1 from each of the river stations $\mathrm{R} 1$ and $\mathrm{R} 2$ (RIVER-1, RIVER-2), and 2 each (representing the $>3 \mu \mathrm{m}$ and 3 to $0.22 \mu \mathrm{m}$ fractions) from the inshore $\mathrm{Z} 2$ station and offshore 65 station. The marine libraries representing the total archaeal community were named INSHORE and OFFSHORE and were from the 2 size fractions ( $>3$ and $<3 \mu \mathrm{m}$ ). Colonies were transferred to 96-well plates containing Luria-Bertani medium with $7 \%$ glycerol. Inserted 16S rRNA sequences were amplified with the vectors' M13 primers. PCR products were digested with TaqI (Invitrogen) for $2 \mathrm{~h}$ at $72^{\circ} \mathrm{C}$ and separated on $3 \%$ lowmelting point agarose gel for $5 \mathrm{~h}$ at $80 \mathrm{~V}$. For each library, clones were collected on 96-well plates and analysed by restriction fragment length polymorphism (RFLP). Colonies showing distinct RFLP patterns were sequenced (single read) using the vectors' T7p universal primer. At least 2 representatives of the most numerous RFLP groups from each sample were sequenced to verify that closely related sequences were represented by the single pattern. The similarity between sequences from the same pattern was always $>99 \%$. Suspected chimeras were checked by using the basic local alignment search tool (BLAST, Altschul et al. 1990) with sequence segments separated and then using the Chimera check program at Ribosomal Data Project II (Michigan State University; http:// rdp8.cme.msu.edu/cgis/chimera.cgi?su=SSU). Two to 6 chimeras per library were detected and excluded from further analyses; 1 to 3 non-archaeal sequences per library were detected and also excluded. The $16 \mathrm{~S}$ rRNA sequence data obtained in this study were archived in the GenBank database (www.ncbi.nlm. nih.gov/Genbank/index.html) under accession numbers DQ146728 to DQ146762 for marine samples and DQ310380 to DQ310468 for riverine samples.

Diversity calculations and phylogenetic analysis. Rarefaction, library coverage, Shannon-Wiener diversity index $\left(H^{\prime}\right)$ and Chao1 non-parametric richness estimator were calculated as described previously (Galand et al. 2003) and with computer program DOTUR (Schloss \& Handelsman 2005) through a Jukes-Cantor corrected distance matrix using the DNADIST program from PHYLIP (available at http:// evolution.genetics.washington.edu/phylip.html). The 2 river samples with similar physico-chemical conditions were grouped together for diversity calculations. As the river samples were not size-fractionated and therefore represented the total community, the 2 size fractions ( $>3$ and $<3 \mu \mathrm{m}$ ) of the marine libraries were grouped to allow comparison. Phylotypes were defined as containing sequences that were no more than $3 \%$ different from each other, and the $3 \%$ distance level was used for calculation of diversity estimators. Statistical differences in the composition of clone libraries were determined using $\int$-LIBSHUFF 
(http://www.plantpath.wisc.edu/fac/joh/S-libshuff.html) (Schloss et al. 2004).

Sequences were compared to those in the EMBL database using the BLAST server (Altschul et al. 1997) at the European Bioinformatics Institute (www.ebi. ac.uk). Only 1 representative sequence of each RFLP pattern was included in the phylogenetic analyses. The $\sim 800 \mathrm{bp}$ sequences were aligned using the CLUSTAL W package (Higgins et al. 1994) and checked manually. DNADIST from PHYLIP was used to calculate genetic distances with the Kimura-2 model, with 100 data sets obtained by bootstrapping. Phylogenetic trees were estimated with FITCH in PHYLIP. The topology of dendrograms was verified using neighbour-joining and maximum parsimony, and was the same using all 3 methods.

\section{RESULTS}

\section{Environmental conditions}

Sampling was timed to coincide with minimum sea ice conditions, and on the dates of sample collection, the Mackenzie River and inner Beaufort Shelf were ice-free. Surface water temperatures were above freezing in the river and below $0^{\circ} \mathrm{C}$ at both marine sites; salinity was slightly lower inshore than offshore (Table 1) but corresponded to typical Arctic Ocean values (Carmack \& MacDonald 2002). Concentrations of SPM were highest at the river stations and decreased along the south-north transect. SPM was nearly 10 times greater at inshore Stn Z2 than at offshore Stn 65.
DOC and total chl a concentrations followed the same trend (Table 1). Further hydrographic details are given by Garneau et al. (2006).

\section{Diversity and phylogeny}

We retrieved 44 and 37 phylotypes in the clone libraries RIVER-1 and RIVER-2 respectively. The diversity in the river was high, as shown by the estimated number of phylotypes (Chao1, Table 2) and diversity indices $\left(H^{\prime}\right.$, Table 2$)$. The high diversity of the river libraries was confirmed by a low coverage index (Table 2) and a rarefaction curve that did not reach an asymptote (Fig. 2). In contrast to the river, we detected 14 to 15 different phylotypes in the clone libraries from the marine stations. These libraries had coverage indexes of $>90 \%$, indicating good coverage of the natural populations. Diversity was slightly higher at the inshore station, but was much lower than that of the river libraries (Table 2). Pair-wise comparison between riverine and coastal libraries indicated that the libraries were significantly different from one another $(\mathrm{p}<0.001)$.

Most of the clones retrieved from the river were affiliated to Euryarchaeota and belonged to 3 phylogenetic clusters: Methanomicrobiales, Rice Cluster-V (RC-V, Grosskopf et al. 1998b) and Lake Dagow Sediment (LDS, Glissman et al. 2004) (Fig. 3). LDS and RC-V were the most abundant clusters, grouping more than $90 \%$ of the clones. In GenBank, the closest relatives of members of the RC-V clusters were sequences retrieved from freshwater environments, such as lake

Table 1. Environmental characteristics at 2 stations from the Mackenzie River (R1 and R2) and 2 coastal stations from the Beaufort Sea Shelf (Z2 and 65). SPM: suspended particulate matter; DOC: dissolved organic carbon

\begin{tabular}{|c|c|c|c|c|c|c|c|c|}
\hline Stn & $\begin{array}{c}\text { Transect } \\
\text { distance }(\mathrm{km})\end{array}$ & $\begin{array}{c}\text { Sample } \\
\text { depth (m) }\end{array}$ & $\begin{array}{l}\text { Max. depth } \\
\text { (m) }\end{array}$ & $\begin{array}{c}\text { Temp. } \\
\left({ }^{\circ} \mathrm{C}\right)\end{array}$ & $\begin{array}{l}\text { Salinity } \\
\text { (psu) }\end{array}$ & $\begin{array}{c}\mathrm{SPM} \\
\left(\mathrm{mg} \mathrm{l}^{-1}\right)\end{array}$ & $\begin{array}{c}\text { DOC } \\
\left(\mathrm{mg} \mathrm{C} \mathrm{l}^{-1}\right)\end{array}$ & $\begin{array}{l}\text { Chl a } \\
\left(\mu \mathrm{g} \mathrm{l}^{-1}\right)\end{array}$ \\
\hline R1 (river) & 0 & $\sim 0$ & 0.5 & 2.90 & 0.2 & 42.51 & 5.70 & 1.30 \\
\hline R2 (river) & 30 & $\sim 0$ & 0.5 & 3.90 & 0.2 & 27.84 & 4.90 & 1.29 \\
\hline Z2 (inshore) & 125 & 1 & 5 & -0.54 & 25.4 & 17.26 & 2.47 & 0.51 \\
\hline 65 (offshore) & 195 & 2 & 33 & -0.44 & 26.5 & 1.75 & 0.88 & 0.21 \\
\hline
\end{tabular}

Table 2. Diversity of Archaea assemblages in the Mackenzie River and at 2 coastal stations from the Beaufort Sea Shelf (inshore and offshore). Enumeration of phylotypes and calculation of diversity estimators were completed at the $3 \%$ distance level between sequences. RIVER: both libraries were combined to increase precision of statistical calculations; INSHORE and OFFSHORE: both size-fraction libraries ( $>3$ and $<3 \mu \mathrm{m}$ ) were combined to represent total archaeal community (see 'Materials and methods'). Chao1: richness estimator

\begin{tabular}{|lcccccc|}
\hline Stn & No. of phylotypes & $H^{\prime}$ & Chao1 & Coverage of libraries (\%) & No. of clones & No. of libraries \\
\hline RIVER & 76 & 4.2 & 286 & 39.8 & 98 & 2 \\
INSHORE & 14 & 1.5 & 23 & 94.8 & 154 & 2 \\
OFFSHORE & 15 & 1.4 & 18 & 94.7 & 132 & 2 \\
\hline
\end{tabular}




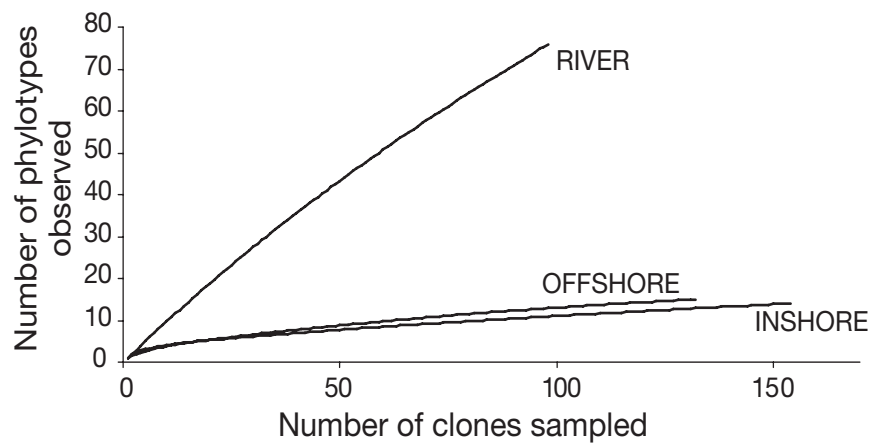

Fig. 2. Rarefaction curve calculated for clone libraries obtained from the Mackenzie River (RIVER) and from 2 marine coastal stations (INSHORE \& OFFSHORE) from the adjacent Beaufort Shelf. Rarefaction was calculated at the $3 \%$ distance level

sediment and rice field soil (Fig. 4). Members of the LDS cluster were also distantly related to sequences retrieved from lake sediments, and also from a deepsea hydrothermal vent (Fig. 4). Members of both the $\mathrm{RC}-\mathrm{V}$ and LDS cluster were represented by very diverse clones; most of them represented different phylotypes. Three clones retrieved from RIVER-1 belonged to the order Methanomicrobiales, family Methanomicrobiaceae, and were most closely related to sequences retrieved from freshwater sediments (Fig. 5).

Marine clone libraries (INSHORE and OFFSHORE) contained a majority of Group II Archaea and, among Group II, the most represented group was II.a (Fig. 3). In GenBank, the most closely related sequences to Group II.a were retrieved from ancient oceanic crust (AY704383) and the Oregon Coast (U11042) (Fig. 5). Group II.b was also represented in all marine libraries but by few clones ( 2 to $7 \%$ of all clones). The most typical Group II.b sequences were distantly related to clones from the Arctic Ocean (AY288409) and Southern Ocean (U11044) (Fig. 5). Clones belonging to the order Methanomicrobiales, genus Methanogenium were only present in marine library OFFSHORE. They were closely related to a sequence from Antarctic sediments (AY177815). A few clones belonging to the LDS and $\mathrm{RC}-\mathrm{V}$ cluster were detected in INSHORE and OFFSHORE libraries. However, sequences were different from those retrieved from the river, and members of the LDS cluster grouped into a separated subcluster (Fig. 4).

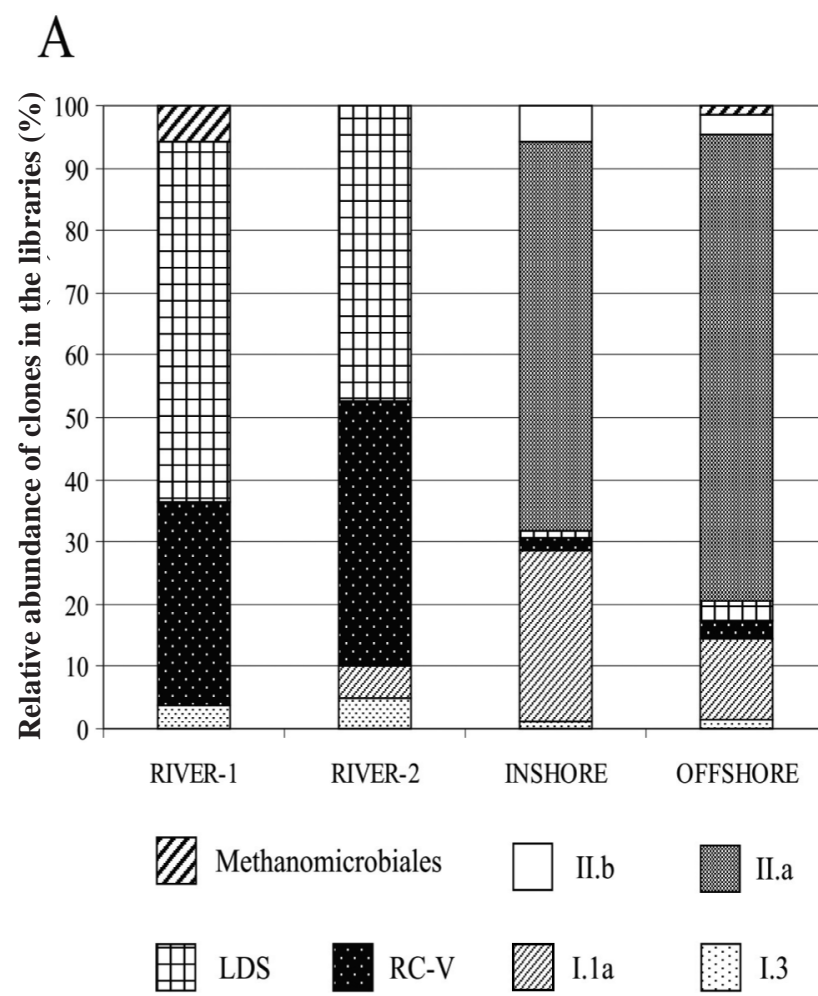

Fig. 3. (A) Archaea community structure in clone libraries RIVER-1 and RIVER-2 from the Mackenzie River, and INSHORE and OFFSHORE from the Beaufort Shelf. Communities are represented by relative abundances of clones in different phylogenetic clusters. (B) Collapsed tree yielding a schematic representation of the phylogenetic position of groups estimated with FITCH from the program PHYLIP, as described in 'Materials and methods'

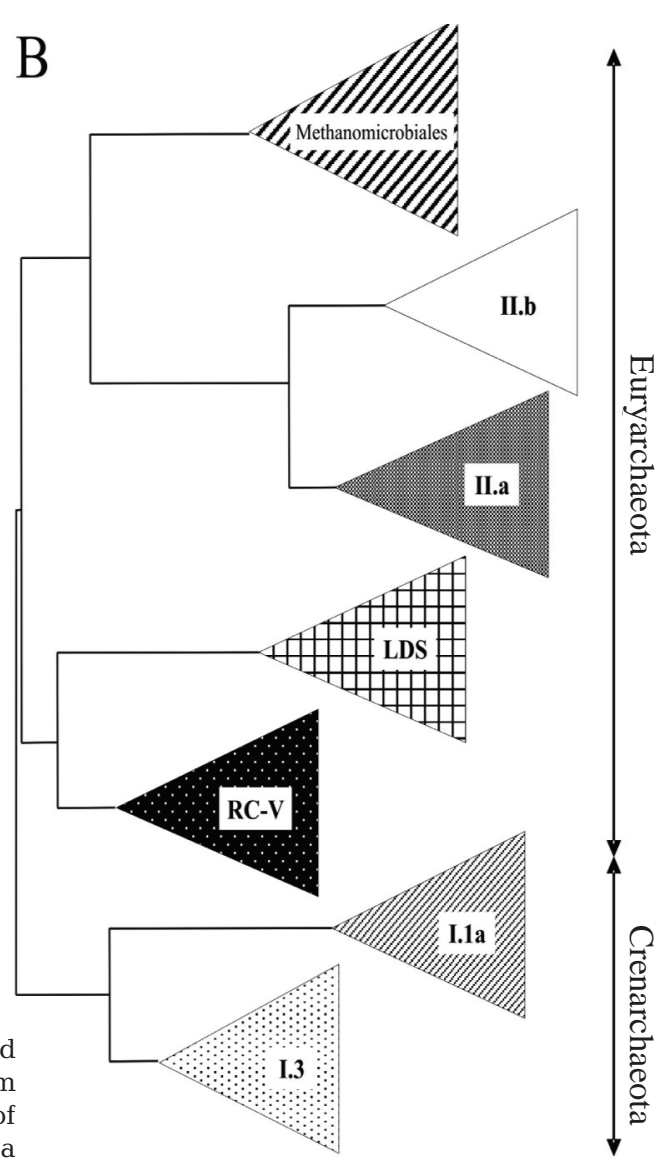

0.1 


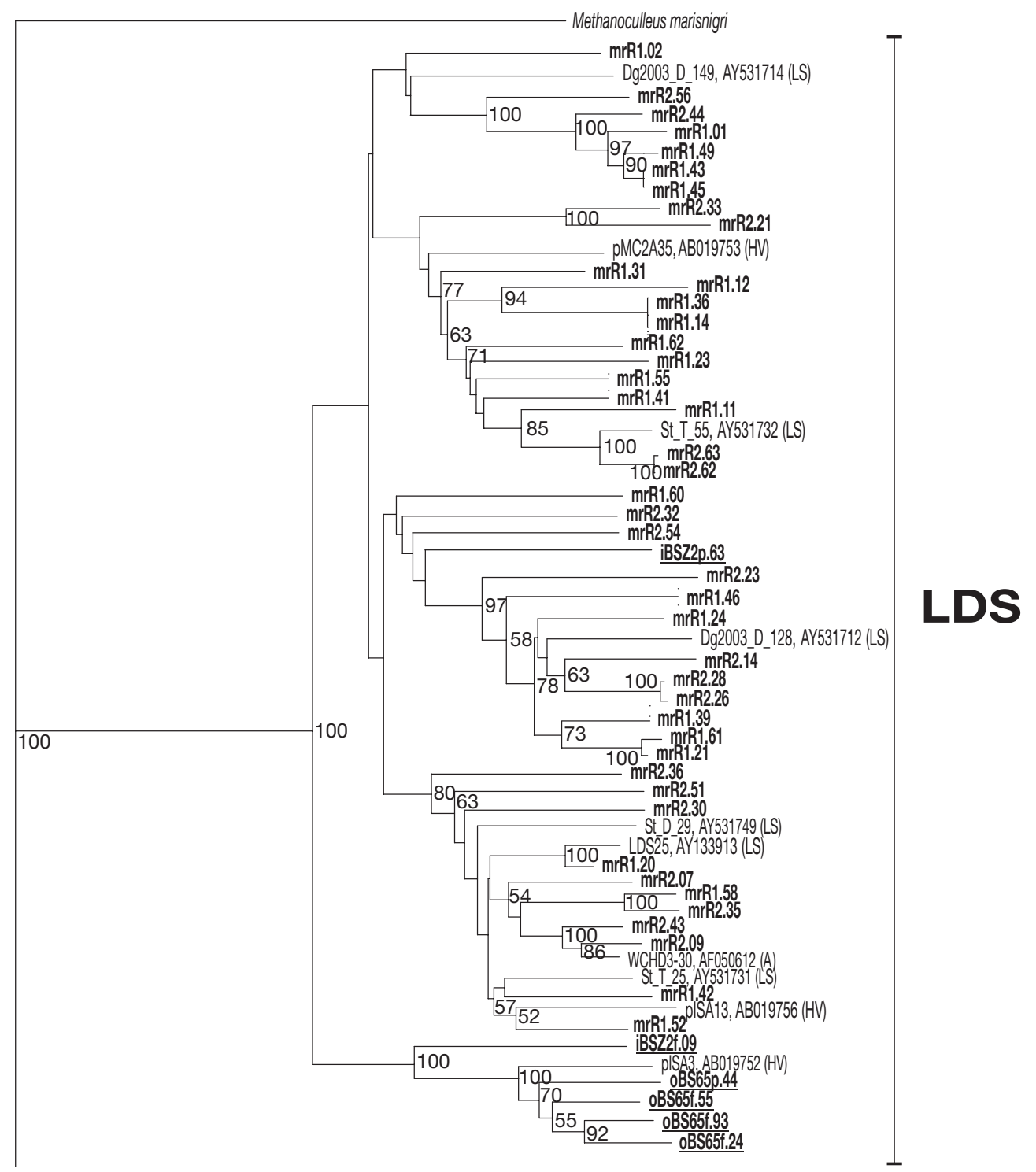

Fig. 4. (Above and facing page.) Phylogenetic tree representing euryarchaeotal LDS and RC-V clusters containing riverine, coastal and other Archaea inferred from 800 bp-long 16S rRNA sequences using FITCH (from the program PHYLIP) distance matrix analysis. Bootstrap values $>50$ are indicated; ' $p$ ' (particle) and ' $\mathrm{f}$ ' (free) at the end of sequence names indicate $>3$ and $<3 \mu \mathrm{m}$ size-fraction source libraries, respectively. Origin of the reference clones: LS, lake sediment; MS, marine sediment; A, aquifer; RFS, rice field soil; HV, hydrothermal vent. Scale bar: $10 \%$ sequence divergence

Crenarchaeota were detected in all libraries. Most of them were retrieved from the coastal marine stations and belonged to Group I.1a Archaea (Fig. 3), according to earlier nomenclature (DeLong 1998). The most common Group I.1a sequence had closest GenBank matches to sequences from habitats such as Antarctic surface water (AF393307), hydrothermal sediments (AF419646) and coral surface (AY380664) (Fig. 6). Newly defined clusters of Crenarchaeota, Group I.3a and 1.3b (Ochsenreiter et al. 2003), were detected in all libraries and contained representatives related to sequences previously retrieved from hydrothermal sediments (AY354118), marine sediment (AJ704633) and contaminated soil (AB161343). We tentatively designated 1 phylotype grouped within a new cluster as Group I.3c. It had 77 to $79 \%$ similarity to clusters I.3a and I.3b and was related to sequences from coral surface (AY380684) and marine sediments (AB188809) (Fig. 6).

In the marine libraries constructed from the biomass fraction $>3 \mu \mathrm{m}$, which represents the particle-associated portion of the archaeal assemblage, the typical riverine groups RC-V and LDS were not more represented than in the $<3 \mu \mathrm{m}$ fraction (results not shown). 

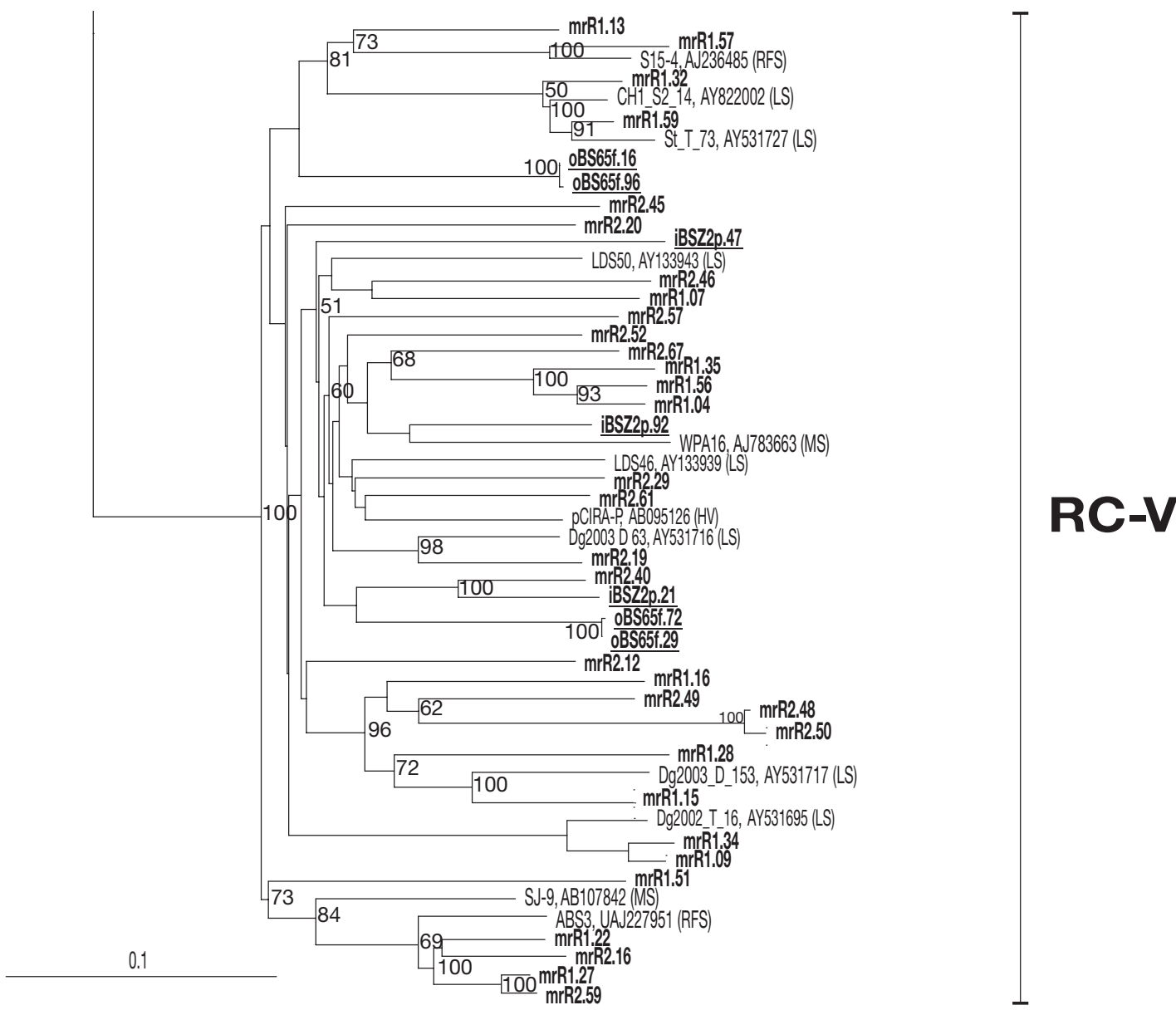

Fig. 4 (continued)

\section{DISCUSSION}

\section{Composition of river Archaea assemblage}

The diversity of Archaea in the Mackenzie River was remarkably high and much greater than archaeal diversity previously reported for rivers at temperate and tropical latitudes (Crump \& Baross 2000, Dumestre et al. 2002, Gonzalez-Toril et al. 2003). Our archaeal diversity was also much greater than that reported from some riverine bacterial assemblages, defined by the Shannon-Wiener diversity index $\left(H^{\prime}\right)$ or the number of different sequences (Sekiguchi et al. 2002, Troussellier et al. 2002), and twice as high as the large bacterioplankton diversity recently described in 2 temperate rivers and defined by the Chaol estimator (Crump \& Hobbie 2005). In part, our detection of this high diversity may be the result of our use of an Archaea primer set that has been developed and applied with success to soil, but not previously to marine and freshwater pelagic ecosystems. It may also reflect properties of the Mackenzie River, which is the most sediment-laden of all the large arctic inflows (Carson et al. 1998). These particle-rich waters are likely to provide diverse micro-habitats that are conducive to multiple niches and species. Finally, large rivers, which to date have been little sampled for microbial diversity, could in general have an unusually high microbial molecular diversity because they are heterogeneous ecosystems. They receive inputs of allochthonous microbiota and complex mixtures of dissolved and particulate substrates from diverse sub-catchments.

Most of the archaeal sequences detected in the river belonged to LDS and RC-V clusters. This is the first report of these phylotypes in rivers. The few archaeal sequences previously retrieved from riverine waters were found in an equatorial river, Order Methanomicrobiales and Thermococcales (Dumestre et al. 2002), in an acidic river, Order Thermoplasmatales (Gonzalez-Toril et al. 2003), and in a temperate river, Phylum Crenarchaeota (Crump \& Baross 


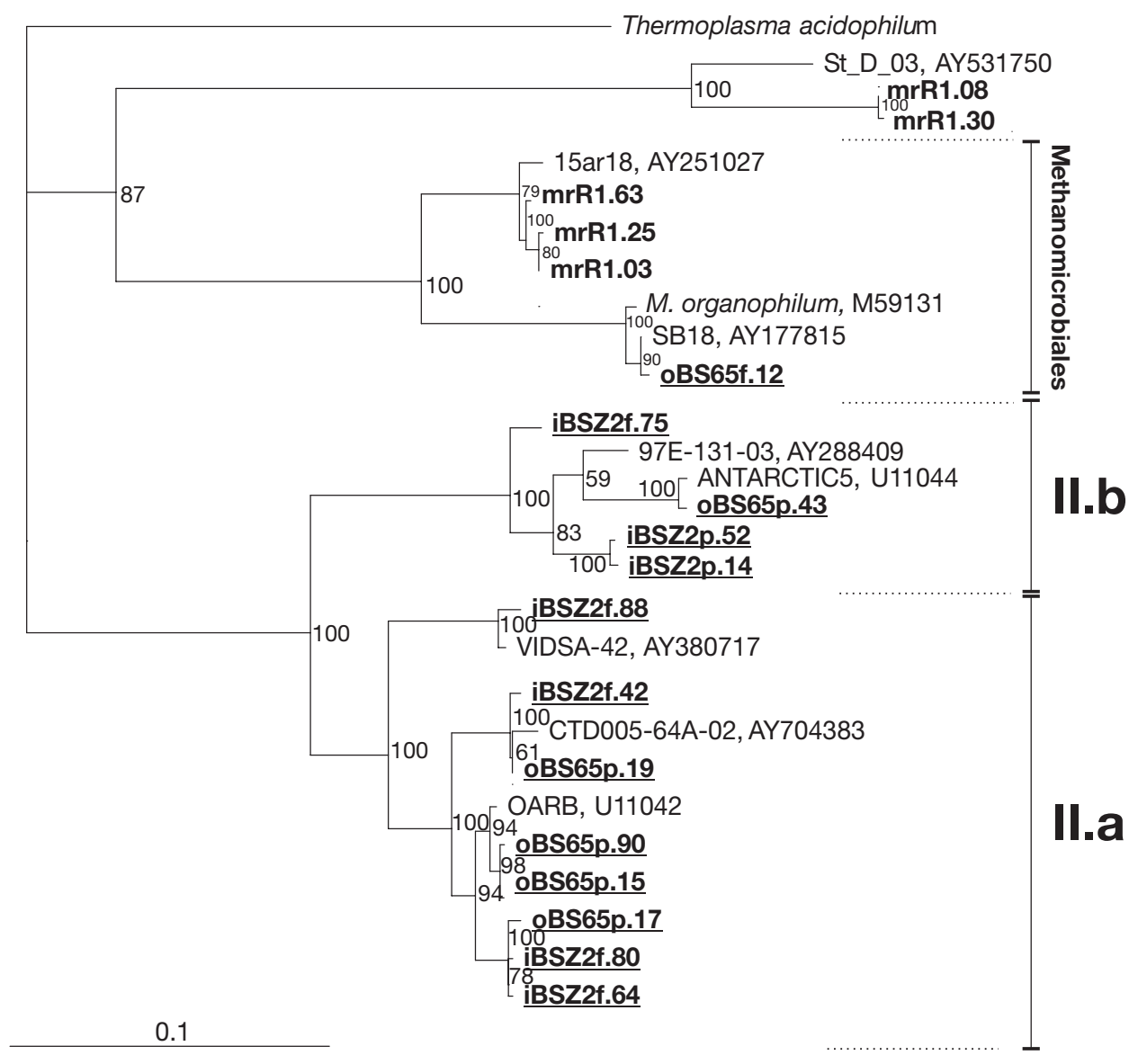

Fig. 5. Phylogenetic tree representing Methanomicrobiales and environmental euryarchaeotal Group II.a and II.b containing riverine, coastal and other Archaea inferred from 800 bp-long 16S rRNA sequences using FITCH (from the program PHYLIP) distance matrix analysis. Bootstrap values $>50$ are indicated; ' $\mathrm{p}$ ' and ' $\mathrm{f}$ ' at the end of sequence names indicate $>3$ and $<3 \mu \mathrm{m}$ size-fraction source libraries, respectively. Scale bar: $10 \%$ sequence divergence

2000). LDS cluster sequences were originally retrieved from temperate lake sediments (Glissman et al. 2004), but our sequences were also affiliated with sequences from deep-sea hydrothermal vents (Fig. 4). Members of RC-V were originally retrieved from rice field soils (Grosskopf et al. 1998b), but planktonic freshwater representatives have been recently detected in a pond (Slapeta et al. 2005). Our RC-V sequences were also related to environmental clones from temperate lakes and marine sediments. Detection of numerous LDS and RC-V sequences in the Mackenzie River provides novel data on the distribution of those Archaea. They appear to occupy a variety of habitats ranging from temperate submerged soil and sediments to arctic running freshwater. The low level of DNA identity among our Mackenzie River sequences and sequences from elsewhere indicate that LDS and $\mathrm{RC}-\mathrm{V}$ are phylogenetically very diverse groups.
The high diversity of the river Archaea is intriguing, and the question remains as to whether the broad phylogenetic diversity is reflected in a diversity of physiological roles. Even though the specific functional roles of these Archaea remain unknown, their common occurrence in sediments and soils and their prevalence in the particle-rich Mackenzie River indicate that these groups of organisms are probably linked to detrital decomposition. This includes those organisms that directly use organic carbon or organic chemicals as an electron donor, and others with a lower position in the decomposition chain with a chemolithoautotrophic physiological strategy. Northern permafrost soils contain globally significant amounts of organic carbon, and there is increasing concern about the mechanisms that could be involved in converting these carbon stocks to greenhouse gases as the permafrost continues to warm and melt (Davidson \& Janssens 2006). 


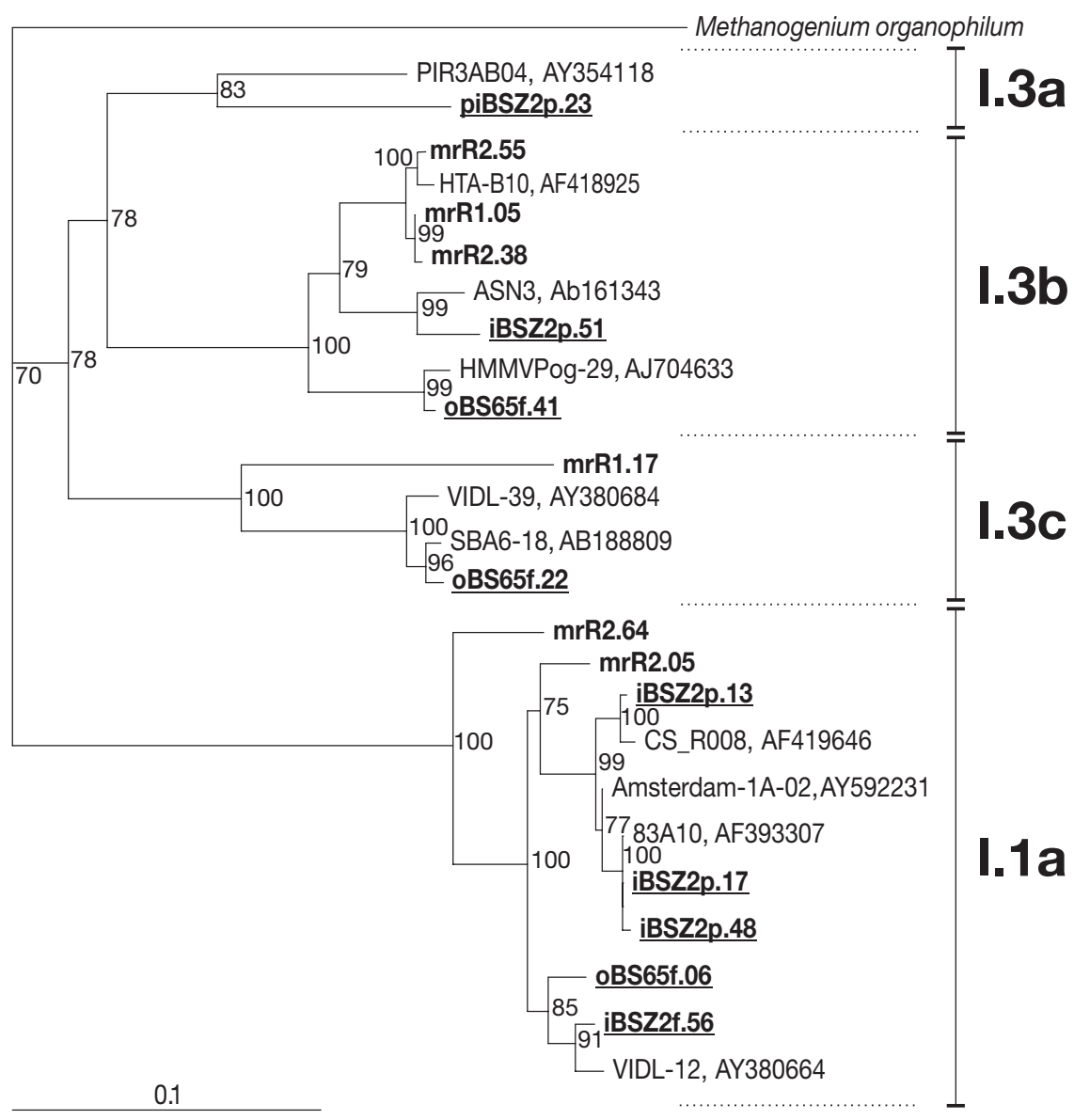

Fig. 6. Phylogenetic tree representing Crenarchaeota Group I.1a, I.3a, I.3b, I.3c including riverine, coastal and other Archaea inferred from $800 \mathrm{bp}$-long 16S rRNA sequences using FITCH (from the program PHYLIP) distance matrix analysis. Bootstrap values $>50$ are indicated; ' $\mathrm{p}$ ' and ' $\mathrm{f}$ ' at the end of sequence names indicate $>3$ and $<3 \mu \mathrm{m}$ size-fraction source libraries, respectively. Scale bar: $10 \%$ sequence divergence

\section{Composition of marine coastal archaeal assemblage}

Group II Euryarchaeota were the most common group of sequences from both INSHORE and OFFSHORE libraries. This result differs from an earlier study in the Arctic Ocean that reported nearly twothirds of surface mixed layer clones belonged to Group I Crenarchaeota (Bano et al. 2004). This difference in archaeal composition may reflect differences in sampling locations, depth and primer specificity. The earlier samples (Bano et al. 2004) were collected by submarine from underneath the ice-covered central Arctic Ocean at $55 \mathrm{~m}$ at the base of the upper mixed layer, whereas our samples were from a seasonally ice-free shelf and near the surface. Depth is thought to be important in structuring Archaea populations, with Group I Archaea becoming more abundant with increasing depth (Massana et al. 1997, 2000, Karner et al. 2001). The Beaufort Shelf is also influenced by the large discharge of the Mackenzie River, and this freshwater inflow influences the physico-chemical conditions of the coastal sea by reducing salinity and increasing particle loads (Carmack \& MacDonald 2002). In turn, these abiotic factors influence phytoplankton productivity (Carmack et al. 2004) and bacterial community structure (Kirchman et al. 2004); furthermore, particle concentration has been found to correlate with archaeal abundance (Wells et al. 2006).

Previous studies of marine archaeal assemblages (Massana et al. 1997, 2000, Bano et al. 2004) used the primer pair 21f-958r (DeLong 1992). We amplified archaeal DNA using the primer pair 109f-915r (Grosskopf et al. 1998a), which 'in silico' detects a greater number of sequences from different archaeal groups (Banning et al. 2005). The present detection of previously unobserved archaeal phylotypes may be a consequence of primer efficiency. 
The composition of coastal Arctic libraries was also very different from surface Antarctic studies, where Group I Archaea are the dominant phylotype at all depths (Massana et al. 2000). Our libraries also contained more phylotypes than previously reported from different oceanic provinces. Archaeal assemblages were previously reported to be of limited diversity, with 1 or 2 phylotypes dominating most clone libraries (Massana et al. 2000). In our system, we found at least 3 dominant sequence groups in each library, and additional less-abundant clones that formed distinct phylotypes. These differences suggest a greater diversity of marine Archaea than previously thought.

The proportion of Group II Archaea in our coastal Arctic libraries was similar to that described from surface samples of a temperate ocean (Massana et al. 2000). However, the detailed composition of Group II sequences differed significantly. While previous studies reported dominance by Group II.b (Massana et al. 2000, Bano et al. 2004), we found mostly Group II.a. Moreover, the Group II.a sequences from our coastal Arctic libraries were not the same as those previously found to be ubiquitous over broad oceanic regions (II-BB; Massana et al. 2000). The Beaufort Shelf libraries also revealed clusters of Archaea that were not previously detected in oceanic assemblages: RC-V and LDS clusters and sequences related to Methanogenium sp., a hydrogen-utilising methanogen previously retrieved from Antarctic coastal marine sediments.

The majority of crenarchaeotal sequences retrieved from the Beaufort Shelf grouped within the cluster I.1a. Group I.1a sequences were the sole Crenarchaeota previously retrieved from Arctic surface water (Bano et al. 2004). The marine Mackenzie shelf libraries contained 3 additional groups of Crenarchaeota (I.3a, I.3b and I.3c). Members of I.3b were previously retrieved from freshwater, wastewater and soil (Ochsenreiter et al. 2003), and our phylotypes were also related to sequences from marine sediments. These sequences may be unique to the freshwater-influenced Arctic shelf system, or alternatively may reflect the different specificity of the primers used in the present study. The most common Group I.1a clones in our libraries were not the same as those dominating other oceanic assemblages (Massana et al. 2000). On the Mackenzie Shelf, the most common crenarchaeotal clone was closely related to the OTU I-IA group described by Massana et al. (2000), which they only detected once. In addition, the 2 most common oceanic sequences reported by Massana et al. (2000) (I-AA and I-CD) were not detected in our libraries. The most frequent Group I.1a clones retrieved from mixed surface water in the survey of central Arctic Archaea (Bano et al. 2004) corresponds to common I.1a sequences in our coastal Arctic libraries. Even though the specific function of the organisms from this coastal Arctic environment remains unknown, the recent isolation of a Group I marine Crenarchaeota that grows chemolithoautotrophically by aerobically oxidizing ammonia to nitrite (Konneke et al. 2005) suggests that nitrifying marine Crenarchaeota contribute to global carbon and nitrogen cycles.

\section{Possible allochthonous origin of marine coastal Archaea}

Marine coastal populations of Archaea had no similarity to the river community and were therefore more likely to be autochthonous, unless derived from river communities advected into the coastal environment much earlier in the year, for example during peak discharge 2 to 3 mo previously. Several lines of evidence counter this latter explanation, and instead support the notion of an autochthonous coastal marine archaeal community. The phylogenetic composition of the clone libraries was totally different in the river (LDS and RC-V) compared with sea (Group II.a and I.1a). The marine coastal libraries contained a majority of archaeal groups that were typically marine, with representatives previously detected in various oceanic regions (Massana et al. 2000, Bano et al. 2004). Additionally, no sequences retrieved from the sea were the same or closely similar to sequences from the river. A few representatives of the LDS and RC-V clusters were detected in the sea, but most of those sequences grouped in sub-clusters distinct from the river clusters (Fig. 4). Finally, although the river discharges large quantities of particles into the adjacent coastal region of the Beaufort Shelf, typical riverine sequences were not more represented in libraries constructed from the $>3 \mu \mathrm{m}$ particle-associated communities. Instead, these particle-associated assemblages were dominated by marine archaeal groups II.a and I.1a.

In contrast, archaeal assemblages in the Mackenzie River have a possible allochthonous origin: the most common sequences in the river belonged to $\mathrm{RC}-\mathrm{V}$ and LDS, phylogenetic groups that contain sequences retrieved previously from flooded soils and sediments (Grosskopf et al. 1998b, Glissman et al. 2004). The tundra of the Mackenzie River catchment area is scattered with lakes, ponds, peatlands and eroding permafrost soils (Woo \& Thorne 2003). These provide a source of particles to the river and could also transport an active Archaea assemblage. While archaeal communities in the river are related to soil and sediment groups, we did not investigate adjacent soils and ponds and so the potential allochthonous input of active Archaea into the river remains speculative. 
In summary, our results point to the importance of Archaea as a diverse constituent of northern high latitude aquatic ecosystems. Contrary to our expectation based on published correlations between Archaea and particles in this system, the marine and freshwater communities were distinct from each other. The high diversity in the Mackenzie River likely reflects the heterogeneous range of substrates and microbiota that enter the river from diverse parts of its catchment, including flooded soils and degrading permafrost. In coastal waters, archaeal diversity was higher than reported elsewhere in the ocean. However, this may be a consequence of the use of a broader-range primer pair-further testing of primers in marine waters is required. Nevertheless, within the context of earlier studies that linked archaeal abundance with high particle loads (Wells et al. 2003, 2006, Garneau et al. 2005), the high diversity of Archaea suggests that high particle environment consortia developed independently in both the river and sea.

Acknowledgements. This study was made possible with financial support from the Natural Sciences and Engineering Research Council of Canada (NSERC), the Canada Research Chair program, Fonds Québécois de Recherche sur la Nature et les Technologies (FQRNT) and Indian and Northern Affairs Canada. We thank M. Fortier (Chief Scientist), L. Miller, M.-E. Rail, M. Robert, and officers and crew of CCGS 'PierreRadisson'. We are also grateful to C. Martineau for fieldwork and analysis, and to L. Retamal for DOC data. This is a contribution to the Canada Arctic Shelf Exchange Study (CASES) under the overall direction of L. Fortier.

\section{LITERATURE CITED}

Altschul SF, Gish W, Miller W, Myers EW, Lipman DJ (1990) Basic local alignment search tool. J Mol Biol 215:403-410

Altschul S, Madden T, Schaffer A, Zhang J, Zhang Z, Miller W, Lipman D (1997) Gapped BLAST and PSI-BLAST: a new generation of protein database search programs. Nucleic Acids Res 25:3389-3402

Banning N, Brock F, Fry JC, Parkes RJ, Hornibrook ERC, Weightman AJ (2005) Investigation of the methanogen population structure and activity in a brackish lake sediment. Environ Microbiol 7:947-960

Bano N, Ruffin S, Ransom B, Hollibaugh JT (2004) Phylogenetic composition of Arctic Ocean archaeal assemblages and comparison with Antarctic assemblages. Appl Environ Microbiol 70:781-789

Carmack EC, MacDonald RW (2002) Oceanography of the Canadian shelf of the Beaufort Sea: a setting for marine life. Arctic 55:29-45

Carmack EC, MacDonald RW, Jasper S (2004) Phytoplankton productivity on the Canadian Shelf of the Beaufort Sea. Mar Ecol Prog Ser 277:37-50

Carson M, Jasper J, Conly F (1998) Magnitude and sources of sediment input to the Mackenzie Delta, Northwest Territories. Arctic 51:116-124

Church MJ, DeLong EF, Ducklow HW, Karner MB, Preston CM, Karl DM (2003) Abundance and distribution of planktonic Archaea and bacteria in the waters west of the
Antarctic Peninsula. Limnol Oceanogr 48:1893-1902

Crump BC, Baross JA (2000) Archaeaplankton in the Columbia River, its estuary and the adjacent coastal ocean, USA FEMS Microbiol Ecol 31:231-239

Crump BC, Hobbie JE (2005) Synchrony and seasonality in bacterioplankton communities of two temperate rivers. Limnol Oceanogr 50:1718-1729

Davidson EA, Janssens IA (2006) Temperature sensitivity of soil carbon decomposition and feedbacks to climate change. Nature 440:165-173

DeLong E (1992) Archaea in coastal marine environments. Proc Natl Acad Sci USA 89:5685-5689

DeLong EF (1998) Everything in moderation: Archaea as 'non-extremophiles'. Curr Opin Genet Dev 8:649-654

Delong EF, Wu KY, Prezelin BB, Jovine RVM (1994) High abundance of Archaea in antarctic marine picoplankton. Nature 371:695-697

DeLong EF, King LL, Massana R, Cittone H, Murray A, Schleper C, Wakeham SG (1998) Dibiphytanyl ether lipids in nonthermophilic crenarchaeotes. Appl Environ Microbiol 64:1133-1138

Dumestre JF, Casamayor EO, Massana R, Pedros-Alio C (2002) Changes in bacterial and archaeal assemblages in an equatorial river induced by the water eutrophication of Petit Saut dam reservoir (French Guiana). Aquat Microb Ecol 26:209-221

Fuhrman JA, McCallum K, Davis AA (1992) Novel major archaebacterial group from marine plankton. Nature 356:148-149

Galand PE, Fritze H, Yrjala K (2003) Microsite-dependent changes in methanogenic populations in a boreal oligotrophic fen. Environ Microbiol 5:1133-1143

Garneau ME, Vincent WF, Alonso-Sáez L, Gratton Y, Lovejoy C (2005) Prokaryotic community structure and heterotrophic production in a river-influenced coastal arctic ecosystem. Aquat Microb Ecol 42:27-40

Glissman K, Chin KJ, Casper P, Conrad R (2004) Methanogenic pathway and archaeal community structure in the sediment of eutrophic Lake Dagow: effect of temperature. Microb Ecol 48:389-399

Gonzalez-Toril E, Llobet-Brossa E, Casamayor EO, Amann R, Amils R (2003) Microbial ecology of an extreme acidic environment, the Tinto River. Appl Environ Microbiol 69:4853-4865

Grosskopf R, Janssen PH, Liesack W (1998a) Diversity and structure of the methanogenic community in anoxic rice paddy soil microcosms as examined by cultivation and direct 16S rRNA gene sequence retrieval. Appl Environ Microbiol 64:960-969

Grosskopf R, Stubner S, Liesack W (1998b) Novel euryarchaeotal lineages detected on rice roots and in the anoxic bulk soil of flooded rice microcosms. Appl Environ Microbiol 64:4983-4989

Higgins D, Thompson J, Gibson T, Thompson JD, Higgins DG, Gibson TJ (1994) CLUSTAL W: improving the sensitivity of progressive multiple sequence alignment through sequence weighting,position-specific gap penalties and weight matrix choice. Nucleic Acids Res 22:4673-4680

Jurgens G, Glockner FO, Amann R, Saano A, Montonen L, Likolammi M, Munster U (2000) Identification of novel Archaea in bacterioplankton of a boreal forest lake by phylogenetic analysis and fluorescent in situ hybridization. FEMS Microbiol Ecol 34:45-56

Karner MB, DeLong EF, Karl DM (2001) Archaeal dominance in the mesopelagic zone of the Pacific Ocean. Nature 409:507-510

Keough BP, Schmidt TM, Hicks RE (2003) Archaeal nucleic 
acids in picoplankton from great lakes on three continents. Microb Ecol 46:238-248

Kirchman DL, Dittel AI, Findlay SEG, Fischer D (2004) Changes in bacterial activity and community structure in response to dissolved organic matter in the Hudson River, New York. Aquat Microb Ecol 35:243-257

Knap A, Michaels A, Close A, Ducklow H, Dickson A (eds) (1996) Protocols for the Joint Global Ocean Flux Study (JGOFS) core measurements. JGOFS Report No. 19, reprint of the IOC manuals and guides No. 29, Vol 19. UNESCO, Paris,

Konneke M, Bernhard AE, de la Torre JR, Walker CB, Waterbury JB, Stahl DA (2005) Isolation of an autotrophic ammonia-oxidizing marine archaeon. Nature 437: 543-546

Massana R, Murray AE, Preston CM, DeLong EF (1997) Vertical distribution and phylogenetic characterization of marine planktonic Archaea in the Santa Barbara Channel. Appl Environ Microbiol 63:50-56

Massana R, DeLong EF, Pedros-Alio C, Murray AE, Preston CM (2000) A few cosmopolitan phylotypes dominate planktonic archaeal assemblages in widely different oceanic provinces. Appl Environ Microbiol 66:1777-1787

Murray AE, Preston CM, Massana R, Taylor LT, Blakis A, Wu K, DeLong EF (1998) Seasonal and spatial variability of bacterial and archaeal assemblages in the coastal waters near Anvers Island, Antarctica. Appl Environ Microbiol 64:2585-2595

Nusch E (1980) Comparison of different methods for chlorophyll and phaeopigment determination. Arch Hydrobiol 14:14-36

Ochsenreiter T, Selezi D, Quaiser A, Bonch-Osmolovskaya L, Schleper C (2003) Diversity and abundance of Crenarchaeota in terrestrial habitats studied by 16S RNA surveys and real time PCR. Environ Microbiol 5:787-797

Ovreas L, Forney L, Daae FL, Torsvik V (1997) Distribution of bacterioplankton in meromictic lake Saelenvannet, as determined by denaturing gradient gel electrophoresis of PCR-amplified gene fragments coding for 16S rRNA. Appl Environ Microbiol 63:3367-3373

Schloss PD, Handelsman J (2005) Introducing DOTUR, a com-

Editorial responsibility: Jed Fuhrman,

Los Angeles, California, USA puter program for defining operational taxonomic units and estimating species richness. Appl Environ Microbiol 71:1501-1506

Schloss PD, Larget BR, Handelsman J (2004) Integration of microbial ecology and statistics: a test to compare gene libraries. Appl Environ Microbiol 70:5485-5492

Sekiguchi H, Watanabe M, Nakahara T, Xu BH, Uchiyama H (2002) Succession of bacterial community structure along the Changjiang River determined by denaturing gradient gel electrophoresis and clone library analysis. Appl Environ Microbiol 68:5142-5150

Serreze MC, Walsh JE, Chapin FS, Osterkamp T and 6 others (2000) Observational evidence of recent change in the northern high-latitude environment. Clim Change 46: 159-207

Slapeta J, Moreira D, López-García P (2005) The extent of protist diversity: insights from molecular ecology of freshwater eukaryotes. Proc R Soc Lond B 272:2073-2081

Stein JL, Simon MI (1996) Archaeal ubiquity. Proc Natl ACAD Sci USA 93:6228-6230

Strickland J, Parsons T (1972) A practical handbook of seawater analysis. Fisheries Research Board of Canada, Ottawa

Troussellier M, Schafer H, Batailler N, Bernard L and 5 others (2002) Bacterial activity and genetic richness along an estuarine gradient (Rhone River plume, France). Aquat Microb Ecol 28:13-24

Wells LE, Deming JW (2003) Abundance of bacteria, the cytophaga-flavobacterium cluster and Archaea in cold oligotrophic waters and nepheloid layers of the Northwest Passage, Canadian Archipelago. Aquat Microb Ecol 31: 19-31

Wells LE, Cordray M, Bowerman S, Miller LA, Vincent WF, Deming JW (2006) Archaea in particle-rich waters of the Beaufort Shelf and Franklin Bay, Canadian Arctic: clues to an allochthonous origin? Limnol Oceanogr 51:47-59

Williams P (1985) Analysis: organic matter. In: Head P (ed) Practical estuarine chemistry: a handbook. Cambridge University Press, Cambridge, p 160-200

Woo MK, Thorne R (2003) Streamflow in the Mackenzie Basin, Canada. Arctic 56:328-340

Submitted: March 27, 2006; Accepted: July 20, 2006

Proofs received from author(s): September 5, 2006 